\title{
Correction to: Breastfeeding history and the risk of overweight and obesity in middle-aged women
}

Elżbieta Cieśla ${ }^{1 *}$, Ewa Stochmal $^{2}$, Stanisław Głuszek² and Edyta Suliga ${ }^{1}$

\section{Correction to: BMC Women's Health (2021) 21:196} https://doi.org/10.1186/s12905-021-01332-2

Following the publication of the original article [1], we were notified that the titles of the two Supplementary materials had been reversed.

The original article has been corrected.

\author{
References

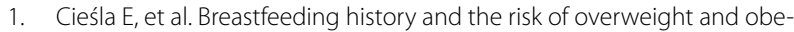 \\ sity in middle-aged women. BMC Women's Health. 2021;21:196. https:// \\ doi.org/10.1186/s12905-021-01332-2.
}

\section{Publisher's Note}

Springer Nature remains neutral with regard to jurisdictional claims in published maps and institutional affiliations.

\section{Author details}

${ }^{1}$ Institute of Health Sciences, Medical College, Jan Kochanowski University, Kielce, Poland. ${ }^{2}$ Institute of Medical Sciences, Medical College, Jan Kochanowski University, Kielce, Poland.

Published online: 16 June 2021 